\title{
Simultaneous determination of various platycosides in Four Platycodon grandiflorum cultivars by UPLC-QTOF/MS
}

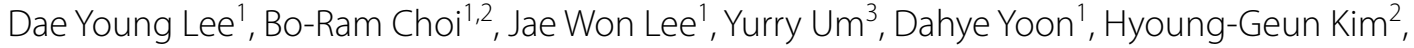 \\ Young-Seob Lee', Geum-Soog Kim', Youn-Hyung Lee ${ }^{4}$ and Nam-In Baek²*
}

\begin{abstract}
In Platycodi Radix (root of Platycodon grandiflorum), there are a number of platycosides that consist of a pentacyclic triterpenoid aglycone and two sugar moieties. Due to the pharmacological activities of platycosides, it is critical to assess their contents in PR, and develop an effective method to profile various platycosides is required. In this study, an analytical method based on ultra performance liquid chromatography coupled with quadrupole time-of-flight/ mass spectrometry (UPLC-QTOF/MS) with an in-house library was developed and applied to profile various platycosides from four different Platycodi Radix cultivars. As a result, platycosides, including six isomeric pairs, were successfully analyzed in the PRs. In the principal component analysis, several platycosides were represented as main variables to differentiate the four Platycodi Radix cultivars. Their different levels of platycosides were also represented by relative quantification. Finally, this study indicated the proposed method based on the UPLC-QTOF/MS can be an effective tool for identifying the detail characterization of various platycosides in the Platycodi Radix.
\end{abstract}

Keywords: Platycosides, Platycodi Radix, Ultra performance liquid chromatography, Quadrupole time-of-flight/mass spectrometry

\section{Introduction}

Platycodi Radix, the root of Platycodon grandiflorum A. De Candolle (Campanulaceae), has been widely used for both cuisine and traditional herbal medicine. The benefits of Platycodi Radix for health and biological activities have been reviewed previously [1]. Platycodi Radix saponins, called platycosides, are the primary constituents of Platycodi Radix, having pharmacological activities such as anti-oxidant, anti-obesity, anti-inflammatory, and anti-cancer effects [2-9]. Thus, it is critical to determine platycosides for the quality control and clinical use of Platycodi Radix. Furthermore, well-constructed analytical platforms are necessary for the effective analysis of platycosides.

\footnotetext{
*Correspondence: nibaek@khu.ac.kr

${ }^{2}$ Graduate School of Biotechnology and Department of Oriental Medicinal Biotechnology, Kyung Hee University, Yongin 17104, Republic of Korea

Full list of author information is available at the end of the article
}

Platycosides consist of a pentacyclic triterpenoid aglycone and two sugar moieties; one is a glucose unit attached at $\mathrm{C}-3$ of a triterpene and the other is a series of three sugars (arabinose, rhamnose, and xylose in sequence) attached at C-28 through an ester linkage with the arabinose. In order to profile platycosides, analytical methods have been previously established by high-performance liquid chromatography (HPLC) coupled to a UV detector $[10,11]$ or by an evaporative light scattering detector (ELSD) $[12,13]$. However, HPLC-UV, or ELSD, shows its limitations in the low sensitivity and the insufficient separation of compounds. Furthermore, these traditional methods need all reference standards for the identification and quantification of each analyte. Thus, LC coupled to the electrospray ionization (ESI)/ mass spectrometry (MS) has been used as an alternative tool to analyze the platycosides in Platycodi Radix [1417]. The mass measurement using MS has provided the selective and sensitive detection of platycosides from the crude extracts of Platycodon grandiflorum. Moreover, the 
tandem MS (MS/MS) has been applied for the structural analysis of various platycosides [18-20].

Platycosides have various structural isomers, according to types of C-3 and C-28 glycosyl groups, attached to triterpenoid aglycone [21]. Although MS/MS has been used to identify the linkage positions and compositions of oligosaccharides, the fragment ions of reducing sugar ring-cleavage have limitations in determining the isomers $[18,20]$. Jeong et al. has recently applied the enzymatic hydrolysis and $\mathrm{MS}^{\mathrm{n}}$ analysis to elucidate the structure of isomers, and nineteen platycosides were successfully identified [22]. However, the need to develop an effective method to comprehensively profile various platycosides still remains.

In this study, we used the ultra-performance LC (UPLC) coupled with the quadrupole time-of-flight (QTOF)/MS to analyze various platycosides. The UPLC system is useful to conduct a quick and effective separation of compounds in a complex mixture. Furthermore, the QTOF/MS is a sensitive and high-resolution detector that effectively provides the exact mass measurement of compounds [23, 24]. In our previous study, an optimal UPLC-QTOF/MS has been applied to profile various metabolites including platycosides [25]. The UPLC system, with its small particle size column, enables a fast and effective separation of various compounds. Furthermore, the QTOF/MS provides a sensitive and highly accurate mass measurement. Finally, we applied the platform based on UPLC-QTOF/MS and an in-house library to perform the comprehensive profiling of high- and lowabundance platycosides, including several isomers.

\section{Materials and methods}

\section{Reagents and standard compounds}

HPLC grade water $\left(\mathrm{H}_{2} \mathrm{O}\right)$, acetonitrile $(\mathrm{MeCN})$, and methanol $(\mathrm{MeOH})$ were purchased from Merck (Darmstadt, Germany). Formic acid was products of SigmaAldrich (St. Louis, MO, United States) and reference standards of seven compounds were isolated from $P$. grandiflorum roots by a series of column chromatography and medium pressure liquid chromatography (MPLC) in our laboratory. Structure of compounds were elucidated based on the mass spectroscopic (MS) and nuclear magnetic resonance (NMR) data with the literature database: platycodin D3 [27], platycoside E [26], platycodin D [28], polygalacin D [27], platyconic acid A [29], and platycodin D2 [27]. The quality of the compounds was $>98.0 \%$ (determined by normalization of the peak areas detected by HPLC with DAD).

\section{Platycodon grandiflorum samples}

Platycodon grandiflorum roots (cultivars: Fuji Blue, Astra Pink, Astra Blue, Jangbaek) were cultivated and preserved for 2 years in the experimental field of the National Institute of Horticultural and Herbal Science (NIHHS-150128), Rural Development Administration (RDA), Chungbuk, Province, Korea, in 2014 (Fig. 1). Voucher specimen (NIHHS1601) was deposited at the herbarium of the Department of Herbal Crop Research, NIHHS, RDA, Chungbuk, Province, Korea. Three $P$. grandiflorum cultivars, including Fuji Blue, Astra Pink, Astra Blue, which were obtained from Swallowtail Garden Seeds (Santa Rosa, CA, USA), and Jangbaek were collected plants grown in a field in NIHHS, Korea.

\section{Sample preparation}

Platycodon grandiflorum roots were dried at $35-40{ }^{\circ} \mathrm{C}$ in a forced-air, convection-drying oven for 2 days after they were washed and weighed. The main roots were used in extraction after removing the fine roots and rhizome. The main roots were pulverized using a cutting mixer (Hanil, Seoul, Korea) and were thoroughly blended, after which the samples were further homogenized using a ball mill (Retsch MM400, Haan, Germany) for the UPLC analyses. An accurately weighed portion $(50 \mathrm{mg})$ of each fine powder was suspended in $40 \mathrm{~mL}$ of $70 \%(\mathrm{v} / \mathrm{v})$ ethanol $(\mathrm{EtOH})$, and ultrasonically extracted for $60 \mathrm{~min}$ at $50{ }^{\circ} \mathrm{C}$. The extract was filtered and evaporated in a vacuum, and the residue was dissolved in $70 \% \mathrm{MeOH}$. The methanol solution was filtered through a $0.22 \mu \mathrm{m}$ membrane, then analyzed directly by UPLC system.

\section{UPLC conditions}

UPLC was performed with a Waters UPLC system (ACQUITY H-Class, Waters Corp., Milford, MA, USA). Separation was achieved on an ACQUITY BEH

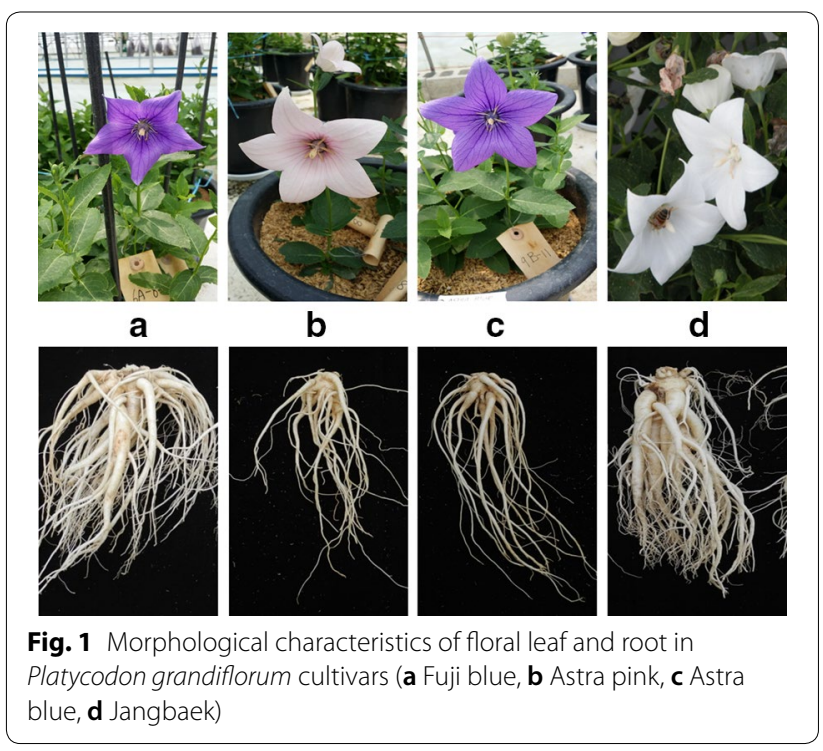


$\mathrm{C}_{18}$ column (130 А, $\left.2.1 \mathrm{~mm} \times 100 \mathrm{~mm}, 1.7 \mu \mathrm{m}\right)$. The column temperature was maintained at $40{ }^{\circ} \mathrm{C}$ and the mobile phase was $5 \% \mathrm{MeCN}$ containing $0.1 \%$ aqueous formic acid (solvent B) and $95 \% \mathrm{MeCN}$ containing $0.1 \%$ aqueous formic acid (solvent $\mathrm{B}$ ). The gradient elution was as follows: $0-3 \mathrm{~min}, \mathrm{~B} 10-20 \%$; $3-11 \mathrm{~min}, \mathrm{~B}$ 20-23\%; 11-20 min, B 23-95\%; 20-21 min, B 95-100\%; 21-25 $\mathrm{min}, \mathrm{B} 100 \%$. The flow rate was $0.45 \mathrm{~mL} / \mathrm{min}$ and the injection volume was $2 \mu \mathrm{L}$ for each run.

\section{QTOF/MS conditions}

MS was performed by using a QTOF/MS (Xevo G2-S, Waters Corp., Milford, MA, USA) that operated in the negative ion mode. The mass detection conditions were optimized in our previous work [25]. The accurate mass measurement and MS/MS analysis were performed at different collision energies ranging from 4 to $45 \mathrm{eV}$ with $\mathrm{MS}^{\mathrm{E}}$ acquisition mode. The operating parameters were set as follows: capillary, $3.0 \mathrm{kV}$; cone voltage, $40 \mathrm{~V}$; source temperature, $120{ }^{\circ} \mathrm{C}$; cone gas flow, $30 \mathrm{~L} / \mathrm{h}$; desolvation temperature, $300{ }^{\circ} \mathrm{C}$; and desolvation gas flow, $600 \mathrm{~L} / \mathrm{h}$. The Q-TOF results were collected between $\mathrm{m} / \mathrm{z} 100-2000$ with contains the internal reference. All analytes were acquired using an independent reference mass using the LockSpray interference to ensure accuracy and reproducibility; Leucine-enkephalin was used as the lock mass $554.262 \mathrm{~m} / z$ (ESI-). The accurate mass was calculated using software UNIFI (Ver. 1.8, Waters Corp., Milford, USA) incorporated in the instrument.

\section{Data processing and multivariate analysis}

After metabolite profiling of $P$. grandiflorum roots by UPLC-QTOF/MS, each set of MS ${ }^{\mathrm{E}}$ data was processed using the UNIFI software. Data within UNIFI were passed through the apex peak detection and alignment processing algorithms. The intensity of each ion was normalized with respect to the total ion count to generate a data matrix having retention time, $m / z$ value, and the normalized peak area. Charged cultivars, salt adducts, and fragments were all automatically aligned and grouped. The three-dimensional data including peak number $(\mathrm{RT}-m / z$ pair), sample name, and normalized peak areas were exported to the EZinfo software 3.0.3 (Umetrics, Umeå, Sweden) for multivariate statistical analyses. Multivariate statistical analyses were performed on the Pareto-scaled and mean-centered Mass spectra of all samples. Principal component analyses (PCA) of the mass spectra were conducted for a spectral pattern comparison of cultivars.

\section{Results and discussion}

\section{Profiling of various platycosides in Platycodi Radix}

\section{by UPLC-QTOF/MS}

To develop an effective method to profile various platycosides from Platycodi Radix, we used the analysis conditions of UPLC-QTOF/MS method constructed in our previous study [25]. By using this method, seven standard samples including platycodin D3, platycoside E, platycodin $\mathrm{D}$, polygalacin $\mathrm{D}$, platyconic acid $\mathrm{A}$, and platycodin D2 were efficiently separated in $15 \mathrm{~min}$. In the negative mode of ESI, these standards were mainly detected as $[\mathrm{M}+\mathrm{HCOO}]^{-}$ions and $[\mathrm{M}-\mathrm{H}]^{-}$ions. The analytical performance of this method has also been proven by validation study. In this study, we applied the method to analyze the various platycosides from four Platycodi Radix cultivars [i.e. Fuji Blue (FB), Astra Pink (AP), Astra Blue $(\mathrm{AB})$, and Jangbaek (JB)]. First, 70\% (v/v) EtOH was used to extract the platycosides from four Platycodi Radix samples, $\mathrm{FB}, \mathrm{AP}, \mathrm{AB}$, and $\mathrm{JB}$, individually; next, each Platycodi Radix extract was analyzed by UPLC-QTOF/ MS; and then processed the data using the UNIFI software. The combination of UPLC separation, Q/TOFMS detection and UNIFI software has been frequently applied in the characterization of chemical constituents of traditional herbs [30]. The total ion chromatogram (TIC) showed the separation and detection of various metabolites, including platycosides from four Platycodi Radix samples (Additional file 1: Figure S1). The extracted ion chromatogram (EIC) and retention time (RT) of various platycosides were listed in the Additional file 1: Figure S2. The $m / z$ of ions from the platycosides profile data were automatically matched to the in-house library compounds [25].

In the complex mixture of the Platycodi Radix extract, it is challenging to identify the various platycosides. The precursor ion $\mathrm{m} / \mathrm{z}$ of the compounds obtained by the exact mass measurement based on QTOF/MS is critical for the identification of platycosides. Furthermore, the alternative high- and low-energy scans conducted by $\mathrm{MS}^{\mathrm{E}}$ mode represents the product ions that assign the structure of the compounds. Thus, we analyzed several standard samples to find the patterns in platycosides of adduction and fragmentation. For example, in the low-energy scan data, platycodin $\mathrm{D}$ was detected as both $[\mathrm{M}+\mathrm{HCOO}]^{-}$and $[\mathrm{M}-\mathrm{H}]^{-}$ions. Furthermore, a specific product ion obtained by the cleavage of a sugar moiety was also found in the high-energy scan data (Additional file 1: Figure S3). To identify the platycosides, it is required to estimate the preceding and product ions in the $M S^{\mathrm{E}}$ data. However, manually determining each platycoside would be time-consuming.

For a fast and exact identification of the various platycosides, we attempted to construct an in-house library 
using the UNIFI software. First, the information of the compound's name and molecular formulas was added into the preliminary library for platycosides. The profiling data of four Platycodi Radix samples was then automatically processed by the preliminary library. As a result, twenty platycosides that do not have isomers were determined based on their exact mass values and product ion data. Otherwise, the information was insufficient to identify six pairs of isomers $\left(\mathrm{C}_{42} \mathrm{H}_{68} \mathrm{O}_{17}, \mathrm{C}_{58} \mathrm{H}_{94} \mathrm{O}_{29}\right.$, $\mathrm{C}_{59} \mathrm{H}_{94} \mathrm{O}_{28}, \mathrm{C}_{63} \mathrm{H}_{102} \mathrm{O}_{32}, \mathrm{C}_{63} \mathrm{H}_{102} \mathrm{O}_{33}$, and $\mathrm{C}_{65} \mathrm{H}_{104} \mathrm{O}_{34}$ ). Although the $\mathrm{MS}^{\mathrm{E}}$ acquisition mode was used to assess the product ion data of six isomeric pairs, it was insufficient to differentiate the isomers by only the glycosidic bond cleavage (Additional file 1: Figure S4).

\section{Determination of platycoside isomers}

To determine seven pairs of platycoside isomers, we focused on examining the elution order of molecules. UPLC-QTOF/MS was used to analyze two standards, platycodin $\mathrm{D} 2$ and platycodin $\mathrm{D} 3$, which are two isomers with the same formula $\left(\mathrm{C}_{63} \mathrm{H}_{102} \mathrm{O}_{33}\right)$. As a result, platycodin D2 (RT: 9.23) had a longer retention time (RT) than platycodin D3 (RT: 5.53) (Fig. 2). According to the position of glucose, platycodin D2 belongs to
Glc- $(1 \rightarrow 3)$-Glc platycosides, and platycodin D3 belongs to Glc- $(1 \rightarrow 6)$-Glc platycosides. Finally, this indicated that Glc- $(1 \rightarrow 3)$-Glc platycosides are eluted later than Glc- $(1 \rightarrow 6)$-Glc platycosides. This rule is then applicable to differentiate Glc- $(1 \rightarrow 3)$-Glc and Glc- $(1 \rightarrow 6)$-Glc platycoside isomers. To identify the isomeric pairs, we manually estimated the processed data representing the observed $m / z$, RT, molecular formula, and adducts. For example, two peaks having different RTs were shown in the BPI chromatogram of $m / z 843.43[\mathrm{M}-\mathrm{H}]^{-}$. They might be platycoside $\mathrm{K}$ and platycoside $\mathrm{L}$ having the same formula $\left(\mathrm{C}_{42} \mathrm{H}_{68} \mathrm{O}_{17}\right)$. According to the chemical structure, platycoside $\mathrm{K}$ belongs to Glc- $(1 \rightarrow 3)$-Glc platycosides, and platycoside L belongs to Glc- $(1 \rightarrow 6)$-Glc platycosides. Thus, the two peaks were determined as platycoside K (RT: 4.35) and platycoside L (RT: 2.59). Platycoside $\mathrm{A}$ and deapioplatycodin $\mathrm{D} 3$ are also two isomers with the same formula $\left(\mathrm{C}_{58} \mathrm{H}_{94} \mathrm{O}_{29}\right)$, and they have Glc$(1 \rightarrow 3)$-Glc and Glc- $(1 \rightarrow 6)-$ Glc, respectively. Hence, platycoside A must be eluted later than deapioplatycodin D3, and the two peaks in the BPI chromatogram of $\mathrm{m} / \mathrm{z}$ $1299.58[\mathrm{M}-\mathrm{H}]^{-}$were determined as platycoside A (RT: 8.3) and deapioplatycodin D3 (RT: 5.18). Polygalacin D2 and platycoside G3, which are two isomers with the same

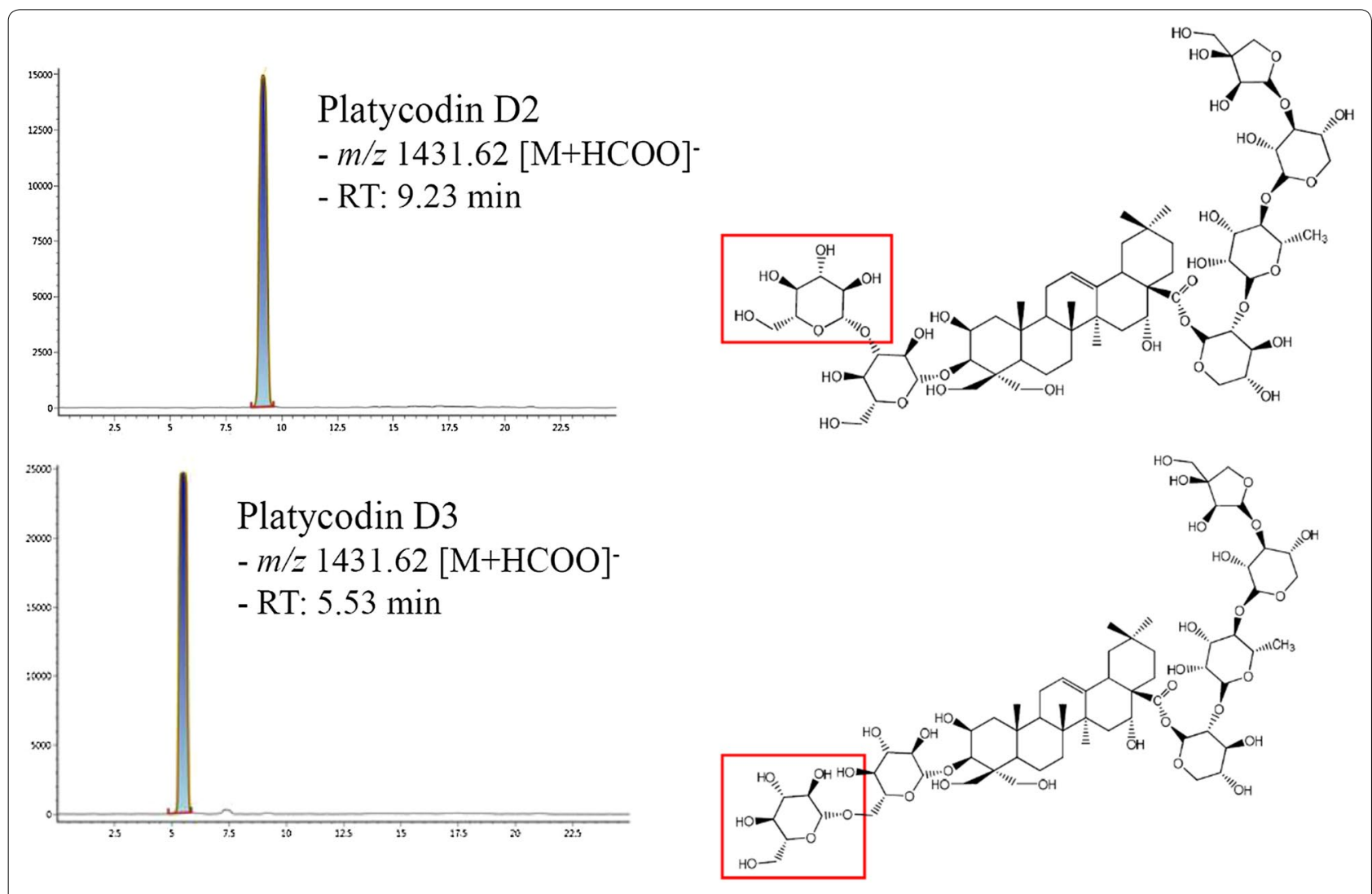

Fig. 2 Separation and identification of two isomers, platycodin D2 (RT: $9.23 \mathrm{~min}$ ) and platycodin D3 (RT: $5.53 \mathrm{~min}$ ), and their molecular structures 
formula $\left(\mathrm{C}_{63} \mathrm{H}_{102} \mathrm{O}_{32}\right)$, have Glc- $(1 \rightarrow 3)$-Glc and Glc$(1 \rightarrow 6)-$ Glc, respectively. Thus, the polygalacin D2 must be eluted later than platycoside G3. Finally, in the BPI chromatogram of $\mathrm{m} / z 1415.63[\mathrm{M}-\mathrm{H}]^{-}$, the two peaks were determined as polygalacin D2 (RT: 9.63) and platycoside G3 (RT: 6.34).

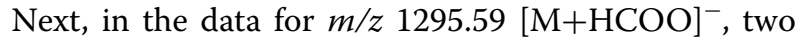
peaks having the same formula $\left(\mathrm{C}_{59} \mathrm{H}_{94} \mathrm{O}_{28}\right)$ might be $3^{\prime}$-O-acetyl-polygalacin $\mathrm{D}$ and $2^{\prime}$-O-acetyl-polygalacin $D$. The structural difference of these two compounds is only the position of an acetyl group (Ac) attached to $\alpha$ - Lrhamnopyranose (Rha), such as Rha $\left(2^{\prime}-O-A c\right)$ and Rha $\left(3^{\prime}-O-A c\right)$. As it is limiting to use these standards, we only relied on a previous report showed that $2^{\prime}-O$-acetylpolygalacin $\mathrm{D}$ is eluted later than $3^{\prime}-O$-acetyl-polygalacin $\mathrm{D}$ [25]. This indicated that Rha $\left(2^{\prime}-O-A c\right)$ platycosides have longer RT than Rha ( $\left.3^{\prime}-\mathrm{O}-\mathrm{Ac}\right)$ platycosides. Thus, the two isomers of formula $\left(\mathrm{C}_{59} \mathrm{H}_{94} \mathrm{O}_{28}\right)$ were determined as $2^{\prime}$-O-acetyl-polygalacin D (RT: 10.79$)$ and $3^{\prime}$-O-acetylpolygalacin D (RT: 8.97) (Fig. 3). We also determined the other isomeric pairs of platycosides as having Rha (2-OAc) or Rha (3-O-Ac). In the data of $m / z 1428.64[\mathrm{M}-\mathrm{H}]^{-}$, two peaks having the same formula $\left(\mathrm{C}_{65} \mathrm{H}_{104} \mathrm{O}_{34}\right)$ might be 3'-O-acetyl-platycodin D2 and 2'-O-acetyl-platycodin D2. 3'-O-acetyl-platycodin D2 has Rha (3-O-Ac) and 2'-O-acetyl-platycodin D2 has Rha (2-O-Ac). Thus, the two isomers were determined as $3^{\prime}-O$-acetyl-platycodin D2 (RT: 9.66) and 2'-O-acetyl-platycodin D2 (RT: 11.84).

\section{Data analysis of four Platycodi Radix samples}

Finally, we identified a total of 32 platycosides, including the six pairs of isomers in Platycodi Radix (Table 1). They include the name of the compound, molecular formula, and observed $m / z$, RT, adducts, and mass accuracy (ppm). This information can be used as database for platycosides profiling. The proposed method based on UPLC-QTOF/MS with an in-house library was used to profile various platycosides from four Platycodi Radix samples. The numbers of individual samples were as follows: FB $(\mathrm{n}=3), \mathrm{AP}(\mathrm{n}=3), \mathrm{AB}(\mathrm{n}=4)$, and JB $(\mathrm{n}=3)$. And then, all the processed data were exported to the EZinfo software for PCA. PCA is an effective tool to visualize the clustering trends among individual samples for finding the similarities or differences between the metabolite data of samples. In the score plot, four groups of $\mathrm{FB}, \mathrm{AP}, \mathrm{AB}$, and JB samples were well separated (Fig. 4A). Moreover, in the loading plot, we identified the main variables that contribute to differentiate the four groups in the score plot. Each point represented the $m / z-$ RT pairs of molecules. Based on the in-house library, the eight variables of loading plot were identified as platycosides (Fig. 4B). This indicated that each Platycodi Radix cultivars showed different contents of platycosides. In the data processing, various platycosides were identified from $\mathrm{FB}(\mathrm{n}=25), \mathrm{AP}(\mathrm{n}=19), \mathrm{AB}(\mathrm{n}=26)$, and JB $(n=26)$. Next, in the MS data, the peak intensities of various platycosides (Mean $\pm S D$ ) were calculated for the

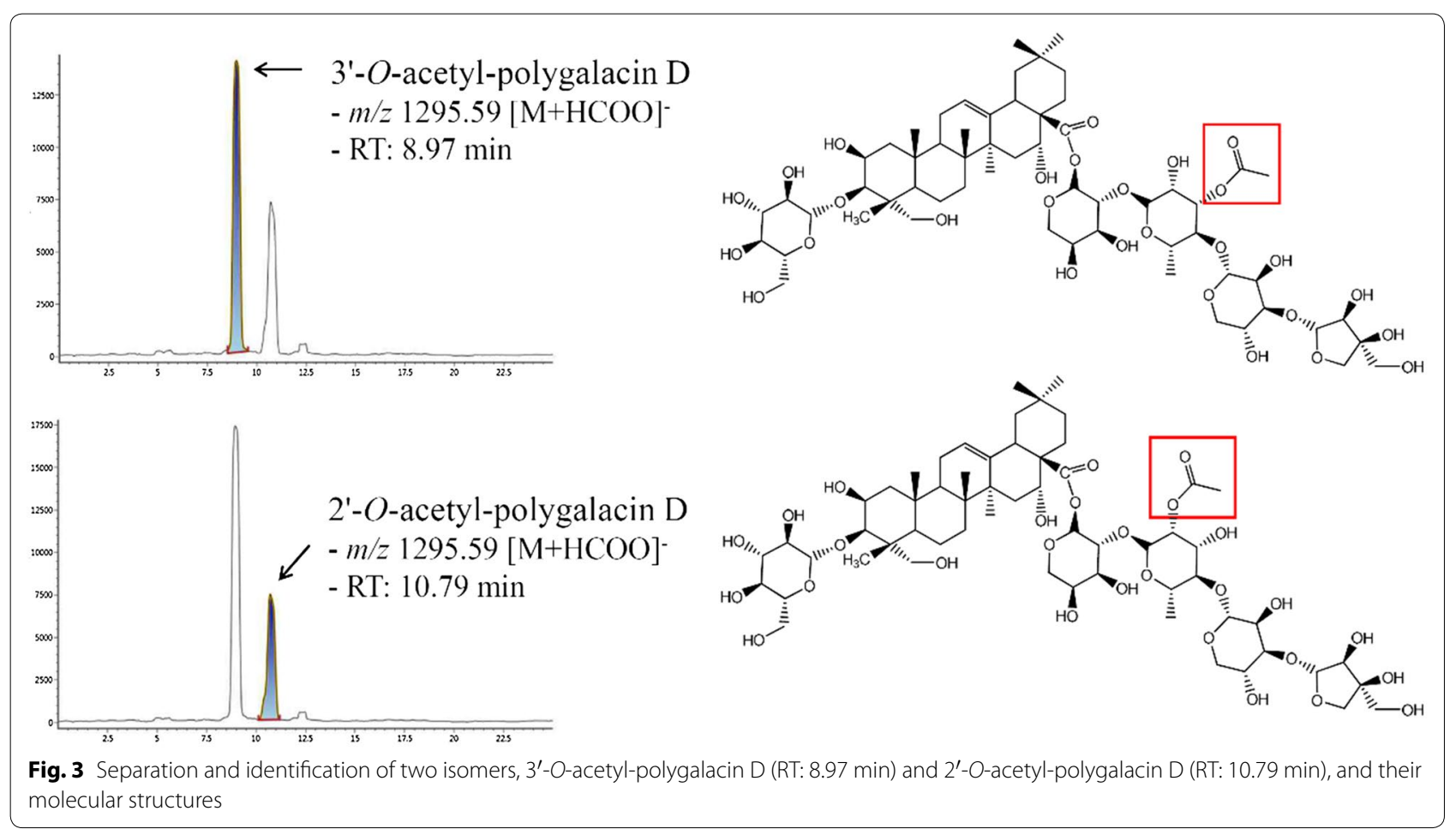


Table 1 The list of various platycosides analyzed in Platycodi Radix (ESI-)

\begin{tabular}{|c|c|c|c|c|c|c|c|c|}
\hline No. & $\mathrm{RT}(\min )$ & Platycosides & Molecular formula & $\begin{array}{l}\text { Expected } \\
\text { neutral mass } \\
(\mathrm{Da})\end{array}$ & $\begin{array}{l}\text { Observed } \\
\text { neutral mass } \\
\text { (Da) }\end{array}$ & QTOF/MS (ESI-) $m / z$ & $\begin{array}{l}\text { Mass } \\
\text { accuracy } \\
(p p m)\end{array}$ & Adducts \\
\hline 1 & 2.59 & platycoside L & $\mathrm{C}_{42} \mathrm{H}_{68} \mathrm{O}_{17}$ & 844.4457 & 844.4449 & 843.4376 & 0.87 & $-\mathrm{H}$ \\
\hline 2 & 3.8 & Platy saponin A & $\mathrm{C}_{42} \mathrm{H}_{68} \mathrm{O}_{16}$ & 828.4507 & 828.4484 & 827.4411 & 2.83 & $-\mathrm{H}$ \\
\hline 3 & 3.9 & Platycoside G1 & $\mathrm{C}_{64} \mathrm{H}_{104} \mathrm{O}_{34}$ & 1416.6409 & 1416.6399 & 1461.6381 & 0.66 & $+\mathrm{HCOO}$ \\
\hline 4 & 4.07 & Platycoside E & $\mathrm{C}_{69} \mathrm{H}_{112} \mathrm{O}_{38}$ & 1548.6832 & 1548.6823 & 1593.6805 & 0.54 & $+\mathrm{HCOO}$ \\
\hline 5 & 4.26 & Platycoside D & $\mathrm{C}_{69} \mathrm{H}_{112} \mathrm{O}_{37}$ & 1532.6882 & 1532.6853 & 1577.6835 & 1.84 & $+\mathrm{HCOO}$ \\
\hline 6 & 4.35 & Platycoside K & $\mathrm{C}_{42} \mathrm{H}_{68} \mathrm{O}_{17}$ & 844.4457 & 844.4421 & 843.4348 & 4.22 & $-\mathrm{H}$ \\
\hline 7 & 5.18 & Deapioplatycodin D3 & $\mathrm{C}_{58} \mathrm{H}_{94} \mathrm{O}_{29}$ & 1254.5881 & 1254.5834 & 1299.5816 & 3.64 & $+\mathrm{HCOO}$ \\
\hline 8 & 5.53 & Platycodin D3 & $\mathrm{C}_{63} \mathrm{H}_{102} \mathrm{O}_{33}$ & 1386.6303 & 1386.6291 & 1431.6273 & 0.84 & $+\mathrm{HCOO}$ \\
\hline 9 & 5.91 & Platycoside H & $\mathrm{C}_{58} \mathrm{H}_{94} \mathrm{O}_{28}$ & 1238.5932 & 1238.5936 & 1283.5918 & 0.34 & $+\mathrm{HCOO}$ \\
\hline 10 & 6.34 & Platycoside G3 & $\mathrm{C}_{63} \mathrm{H}_{102} \mathrm{O}_{32}$ & 1370.6354 & 1370.6409 & 1415.6391 & 3.85 & $+\mathrm{HCOO}$ \\
\hline 11 & 8.3 & Platycoside A & $\mathrm{C}_{58} \mathrm{H}_{94} \mathrm{O}_{29}$ & 1254.5881 & 1254.5853 & 1299.5835 & 2.15 & $+\mathrm{HCOO}$ \\
\hline 12 & 8.31 & Platycoside F & $\mathrm{C}_{47} \mathrm{H}_{76} \mathrm{O}_{20}$ & 960.493 & 960.4908 & 1005.489 & 2.19 & $+\mathrm{HCOO}$ \\
\hline 13 & 8.64 & Deapioplatycodin D & $\mathrm{C}_{52} \mathrm{H}_{84} \mathrm{O}_{24}$ & 1092.5353 & 1092.5343 & 1137.5325 & 0.83 & $+\mathrm{HCOO}$ \\
\hline 14 & 8.97 & 3'-O-Acetyl-polygalacin D & $\mathrm{C}_{59} \mathrm{H}_{94} \mathrm{O}_{28}$ & 1250.5932 & 1250.5937 & 1295.5919 & 0.39 & $+\mathrm{HCOO}$ \\
\hline 15 & 9.13 & Platycoside C & $\mathrm{C}_{54} \mathrm{H}_{86} \mathrm{O}_{25}$ & 1134.5458 & 1134.5461 & 1179.5443 & 0.23 & $+\mathrm{HCOO}$ \\
\hline 16 & 9.23 & Platycodin D2 & $\mathrm{C}_{63} \mathrm{H}_{102} \mathrm{O}_{33}$ & 1386.6303 & 1386.627 & 1431.6252 & 2.3 & $+\mathrm{HCOO}$ \\
\hline 17 & 9.36 & Platycodin D & $\mathrm{C}_{57} \mathrm{H}_{92} \mathrm{O}_{28}$ & 1224.5775 & 1224.5793 & 1269.5775 & 1.44 & $+\mathrm{HCOO}$ \\
\hline 18 & 9.63 & Polygalacin D2 & $\mathrm{C}_{63} \mathrm{H}_{102} \mathrm{O}_{32}$ & 1370.6354 & 1370.6356 & 1415.634 & 0.15 & $+\mathrm{HCOO}$ \\
\hline 19 & 9.66 & 3'-O-Acetyl-platycodin D2 & $\mathrm{C}_{65} \mathrm{H}_{104} \mathrm{O}_{34}$ & 1428.6409 & 1428.644 & 1427.6367 & 2.16 & $-\mathrm{H}$ \\
\hline 20 & 9.78 & Platyconic acid C & $\mathrm{C}_{52} \mathrm{H}_{82} \mathrm{O}_{25}$ & 1106.5145 & 1106.5153 & 1105.508 & 0.7 & $-\mathrm{H}$ \\
\hline 21 & 9.8 & Platycodin C & $\mathrm{C}_{59} \mathrm{H}_{94} \mathrm{O}_{29}$ & 1266.5881 & 1266.5899 & 1311.5881 & 1.42 & $+\mathrm{HCOO}$ \\
\hline 22 & 10.01 & Polygalacin D & $\mathrm{C}_{57} \mathrm{H}_{92} \mathrm{O}_{27}$ & 1208.5826 & 1208.584 & 1253.5822 & 1.11 & $+\mathrm{HCOO}$ \\
\hline 23 & 10.25 & Platyconic acid D & $\mathrm{C}_{54} \mathrm{H}_{84} \mathrm{O}_{26}$ & 1148.5251 & 1148.5261 & 1147.5188 & 0.91 & $-H$ \\
\hline 24 & 10.5 & Platycodin J & $\mathrm{C}_{58} \mathrm{H}_{92} \mathrm{O}_{30}$ & 1268.5673 & 1268.5684 & 1313.5666 & 0.84 & $+\mathrm{HCOO}$ \\
\hline 25 & 10.56 & Platyconic acid A lactone & $\mathrm{C}_{57} \mathrm{H}_{88} \mathrm{O}_{28}$ & 1220.5462 & 1220.5476 & 1219.5403 & 1.15 & $-H$ \\
\hline 26 & 10.62 & Platyconic acid A & $\mathrm{C}_{57} \mathrm{H}_{90} \mathrm{O}_{29}$ & 1238.5568 & 1238.555 & 1237.5477 & 1.43 & $-\mathrm{H}$ \\
\hline 27 & 10.79 & 2'-O-Acetyl-polygalacin D & $\mathrm{C}_{59} \mathrm{H}_{94} \mathrm{O}_{28}$ & 1250.5932 & 1250.5946 & 1295.5928 & 1.08 & $+\mathrm{HCOO}$ \\
\hline 28 & 11.02 & $\begin{array}{l}\text { Methyl-2-O-methylplatyco- } \\
\text { genate A }\end{array}$ & $\mathrm{C}_{59} \mathrm{H}_{94} \mathrm{O}_{29}$ & 1266.5881 & 1266.5858 & 1265.5786 & 1.77 & $-\mathrm{H}$ \\
\hline 29 & 11.25 & Platyconic acid B & $\mathrm{C}_{59} \mathrm{H}_{92} \mathrm{O}_{30}$ & 1280.5673 & 1280.569 & 1279.5617 & 1.32 & $-\mathrm{H}$ \\
\hline 30 & 11.84 & 2'-O-Acetyl-platycodin D2 & $\mathrm{C}_{65} \mathrm{H}_{104} \mathrm{O}_{34}$ & 1428.6409 & 1428.6425 & 1427.6352 & 1.12 & $-\mathrm{H}$ \\
\hline 31 & 11.94 & 16-Oxo-platycodin D & $\mathrm{C}_{57} \mathrm{H}_{90} \mathrm{O}_{28}$ & 1222.5619 & 1222.5633 & 1221.5561 & 1.21 & $-\mathrm{H}$ \\
\hline 32 & 12.01 & Platycodin A & $\mathrm{C}_{59} \mathrm{H}_{94} \mathrm{O}_{29}$ & 1266.5881 & 1266.5888 & 1311.587 & 0.55 & $+\mathrm{HCOO}$ \\
\hline
\end{tabular}

relative quantification of high- and low-abundance platycosides (Table 2). Unfortunately, as it is limiting to use all the platycoside standards, the absolute quantification was not performed. However, this method can be used to compare the relative amount of each platycoside from four different Platycodi Radix cultivars. The developed method was applied to the simultaneous quantification of six major in Platycodi Radix cultivars, respectively. All calibration curves showed good linearity $\left(r^{2}>0.998\right)$ within the test ranges and their contents were listed in 


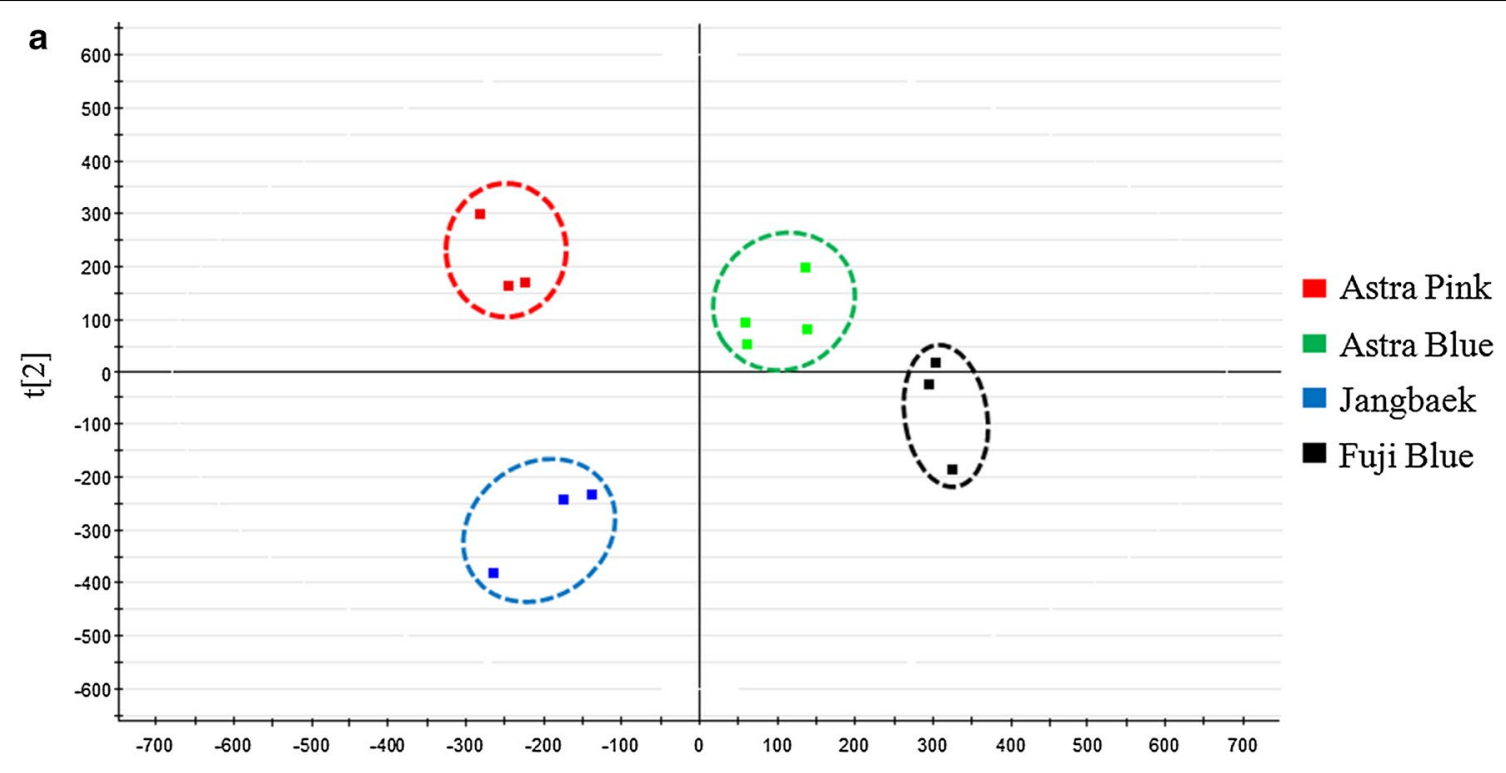

$\mathrm{t}[1]$

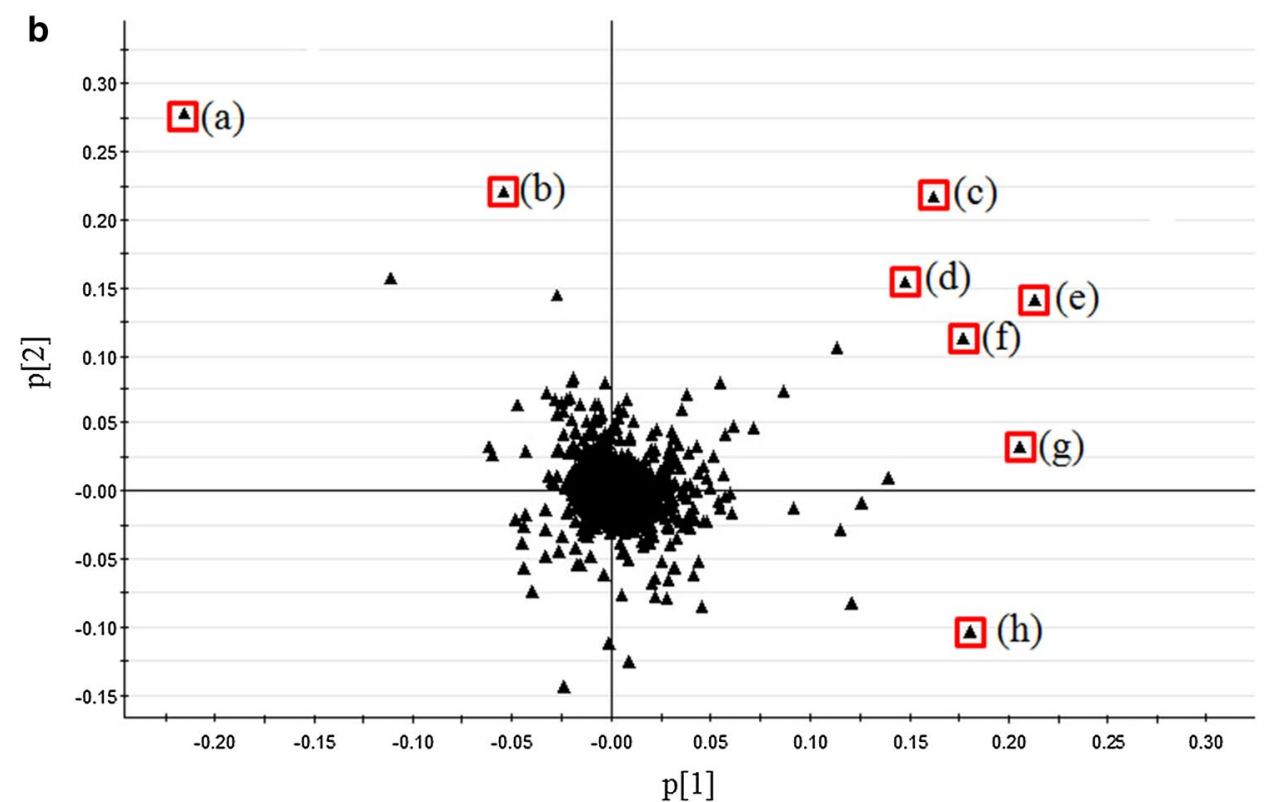

Fig. 4 The principal component analysis (PCA) score plot (A) and loading plot (B) of four Platycodi Radix samples (i.e. Astra Pink, Astra Blue, Jangbaek, Fuji Blue). (a) platyconic acid B, (b) platycoside E, (c) methyl-2-O-methylplatycogenate A, (d) 2'-O-acetyl-platycodin D2, (e) 3'-O-acetyl-platycodin D2, (f) platycodin C, (g) platycodin D, (h) platyconic acid A

Table 3. The results showed that platycosides were the major components in Platycodi Radix and detected in all its samples, but polygalacin D was not found in Fuji Blue and Astra Pink cultivars. Actually, platycosides contribute to the biological activities of Platycodi Radix. Therefore, the platycosides should be considered as the markers for component breeding of Platycodi Radix. 
Table 2 Relative quantification of platycosides from four Platycodi Radix cultivars

\begin{tabular}{|c|c|c|c|c|c|}
\hline No. & Platycosides & Fuji Blue & Astra Pink & Astra Blue & Jangbaek \\
\hline 1 & Platycoside L & $109 \pm 17^{a}$ & $58 \pm 15$ & $52 \pm 21$ & $163 \pm 13$ \\
\hline 2 & Platy saponin A & $797 \pm 171$ & $630 \pm 112$ & $598 \pm 183$ & $753 \pm 82$ \\
\hline 3 & Platycoside G1 & $130 \pm 53$ & $515 \pm 58$ & $150 \pm 25$ & $330 \pm 45$ \\
\hline 4 & Platycoside E & $1992 \pm 160$ & $3507 \pm 426$ & $2436 \pm 338$ & $944 \pm 195$ \\
\hline 5 & Platycoside D & $29 \pm 5$ & $248 \pm 28$ & $36 \pm 16$ & $61 \pm 15$ \\
\hline 6 & Platycoside K & N.D. & N.D. & $60 \pm 12$ & $41 \pm 8$ \\
\hline 7 & Deapioplatycodin D3 & $160 \pm 93$ & N.D. & $62 \pm 38$ & $748 \pm 108$ \\
\hline 8 & Platycodin D3 & $2428 \pm 435$ & $1682 \pm 163$ & $1459 \pm 77$ & $1674 \pm 274$ \\
\hline 9 & Platycoside H & N.D. & N.D. & N.D. & $36 \pm 2$ \\
\hline 10 & Platycoside G3 & $38 \pm 5$ & N.D. & $64 \pm 9$ & $195 \pm 24$ \\
\hline 11 & Platycoside A & $33 \pm 7$ & N.D. & N.D. & N.D. \\
\hline 12 & Platycoside F & $49 \pm 9$ & N.D. & N.D. & $555 \pm 54$ \\
\hline 13 & Deapioplatycodin D & $283 \pm 216$ & $49 \pm 17$ & $98 \pm 23$ & $374 \pm 70$ \\
\hline 14 & 3'-O-Acetyl-polygalacin D & $277 \pm 60$ & $64 \pm 14$ & $149 \pm 24$ & $443 \pm 61$ \\
\hline 15 & Platycoside C & $47 \pm 24$ & N.D. & $44 \pm 24$ & N.D. \\
\hline 16 & Platycodin D2 & $1964 \pm 231$ & $1670 \pm 127$ & $2222 \pm 456$ & $1075 \pm 77$ \\
\hline 17 & Platycodin D & $5370 \pm 1107$ & $2358 \pm 103$ & $4915 \pm 1381$ & $3400 \pm 596$ \\
\hline 18 & Polygalacin D2 & $264 \pm 95$ & $45 \pm 14$ & $7285 \pm 485$ & $3529 \pm 614$ \\
\hline 19 & 3'-O-Acetyl-platycodin D2 & $7033 \pm 1584$ & $6067 \pm 212$ & N.D. & N.D. \\
\hline 20 & Platyconic acid C & $43 \pm 5$ & N.D. & N.D. & N.D. \\
\hline 21 & Platycodin C & N.D. & N.D. & $3978 \pm 791$ & $581 \pm 50$ \\
\hline 22 & Polygalacin D & N.D. & N.D. & $3978 \pm 791$ & $581 \pm 50$ \\
\hline 23 & Platyconic acid D & $115 \pm 30$ & $31 \pm 8$ & $114 \pm 31$ & $452 \pm 37$ \\
\hline 24 & Platycodin J & N.D. & N.D. & N.D. & $94 \pm 10$ \\
\hline 25 & Platyconic acid A lactone & $44 \pm 10$ & N.D. & $22 \pm 0.5$ & N.D. \\
\hline 26 & Platyconic acid $\mathrm{A}$ & $1222 \pm 166$ & $853 \pm 2$ & $1651 \pm 382$ & $1435 \pm 90$ \\
\hline 27 & 2'-O-Acetyl-polygalacin D & N.D. & $56 \pm 15$ & $60 \pm 25$ & $239 \pm 22$ \\
\hline 28 & Methyl-2-O-methylplatycogenate A & $4985 \pm 932$ & $4134 \pm 322$ & $4489 \pm 303$ & $1561 \pm 289$ \\
\hline 29 & Platyconic acid B & $7561 \pm 1187$ & $4105 \pm 59$ & $5756 \pm 117$ & $3452 \pm 734$ \\
\hline 30 & 2'-O-Acetyl-platycodin D2 & $4505 \pm 1203$ & $4538 \pm 487$ & $3369 \pm 191$ & $1546 \pm 589$ \\
\hline 31 & 16-Oxo-platycodin D & N.D. & N.D. & $41 \pm 2$ & N.D. \\
\hline 32 & Platycodin A & $10093 \pm 1068$ & $4503 \pm 460$ & $10169 \pm 435$ & $3704 \pm 121$ \\
\hline
\end{tabular}

N.D. not detection

a The value is mean $\pm S D$

Table 3 Contents of six major platycosides in four Platycodi Radix cultivars

\begin{tabular}{|c|c|c|c|c|c|c|c|}
\hline Platycosides & $\mathrm{RT}$ (min) & $r^{2}$ & Test arranges (ppm) & Fuji Blue (mg/g) & $\begin{array}{l}\text { Astra Pink } \\
(\mathrm{mg} / \mathrm{g})\end{array}$ & $\begin{array}{l}\text { Astra Blue } \\
(\mathrm{mg} / \mathrm{g})\end{array}$ & $\begin{array}{l}\text { Jangbaek } \\
(\mathrm{mg} / \mathrm{g})\end{array}$ \\
\hline Platycoside E & 4.07 & 0.998 & $1.56-100$ & $1.16^{\mathrm{a}}$ & 1.61 & 1.37 & 0.31 \\
\hline Platycodin D3 & 5.53 & 0.998 & $1.56-100$ & 1.35 & 0.72 & 0.58 & 0.77 \\
\hline Platycodin D2 & 9.23 & 0.999 & $1.56-100$ & 1.01 & 0.70 & 1.18 & 0.51 \\
\hline Platycodin D & 9.36 & 0.999 & $1.56-100$ & 2.65 & 1.21 & 2.18 & 1.56 \\
\hline Polygalacin D & 9.63 & 0.999 & $1.56-100$ & N.D. & N.D. & 1.77 & 0.22 \\
\hline Platycogenic acid A & 10.62 & 0.999 & $0.78-100$ & 0.55 & 0.35 & 0.74 & 0.56 \\
\hline
\end{tabular}

a Mean value of samples $(n=3)$ 


\section{Supplementary information}

Supplementary information accompanies this paper at https://doi. org/10.1186/s13765-019-0457-x.

Additional file 1: Figure S1. TIC chromatogram of various metabolites including platycosides from four Platycodi Radix cultivars (i.e. Astra Pink, Astra Blue, Jangbaek, Fuji Blue). Figure S2. EIC chromatogram of various platycosides from Platycodi (Jangbaek cultivar). Figure S3. MS ${ }^{E}$ data and molecular structure of platycodin D. Figure S4. MS ${ }^{\mathrm{E}}$ data of six isomeric pairs of platycosides

\section{Acknowledgements}

This work was supported by the Next Generation Bio-Green 21 (PJ01331002) Project from Rural Development Administration, Republic of Korea.

\section{Authors' contributions}

DYL and N-IB conceived and designed the experiments; DY and $\mathrm{H}-\mathrm{GK}$ isolated the compounds and elucidated the structures; $Y U$ contributed to the plant materials preparation; B-RC performed the mass experiments; $Y$-SL and JWL analyzed the experimental data; DYL wrote the paper; $\mathrm{YHL}$ and $\mathrm{N}-\mathrm{IB}$ managed the research project. G-SK contributed the revision version of the manuscript. All authors helped preparing the paper. All authors read and approved the final manuscript.

\section{Funding}

Rural Development Administration (Republic of Korea), Project Number PJ01331002.

\section{Availability of data and materials}

The datasets used and/or analysed during the current study are available from the corresponding author on reasonable request.

\section{Competing interests}

The authors declare that they have no competing interests.

\section{Author details}

${ }^{1}$ Department of Herbal Crop Research, National Institute of Horticultural and Herbal Science, RDA, Eumseong 27709, Republic of Korea. ${ }^{2}$ Graduate School of Biotechnology and Department of Oriental Medicinal Biotechnology, Kyung Hee University, Yongin 17104, Republic of Korea. ${ }^{3}$ Forest Medicinal Resources Research Center, National Institute of Forest Science, Yeongju 36040, Republic of Korea. ${ }^{4}$ Department of Horticultural Biotechnology, Kyung Hee University, Yongin 17104, Republic of Korea.

Received: 2 June 2019 Accepted: 9 September 2019 Published online: 23 September 2019

\section{References}

1. Nyakudya E, Jeong JH, Lee NK, Jeong YS (2014) Platycosides from the roots of Platycodon grandiflorum and their health benefits. Prev Nutr Food Sci 19:59

2. Ahn KS, Noh EJ, Zhao HL, Jung SH, Kang SS, Kim YS (2005) Inhibition of inducible nitric oxide synthase and cyclooxygenase II by Platycodon grandiflorum saponins via suppression of nuclear factor-kB activation in RAW 264.7 cells. Life Sci J 76:2315-2328

3. Jeong CH, Choi GN, Kim JH, Kwak JH, Kim DO, Kim YJ, Heo HJ (2010) Antioxidant activities from the aerial parts of Platycodon grandiflorum. Food Chem 118:278-282

4. Kim JY, Kim DH, Kim HG, Song GY, Chung YC, Roh SH, Jeong HG (2006) Inhibition of tumor necrosis factor- $\alpha$-induced expression of adhesion molecules in human endothelial cells by the saponins derived from roots of Platycodon grandiflorum. Toxicol Appl Pharmacol 210:150-156

5. Kim YS, Kim JS, Choi SU, Kim JS, Lee HS, Roh SH, Jeong YC, Kim YK, Ryu SY (2005) Isolation of a new saponin and cytotoxic effect of saponins from the root of Platycodon grandiflorum on human tumor cell lines. Planta Med 71:566-568
6. Lee JY, Hwang WI, Lim ST (2004) Antioxidant and anticancer activities of organic extracts from Platycodon grandiflorum A. De Candolle roots. J Ethnopharmacol 93:409-415

7. Ravipati AS, Zhang L, Koyyalamudi SR, Jeong SC, Reddy N, Bartlett J, Smith PT, Shanmugam K, Münch G, Wu MJ (2012) Antioxidant and antiinflammatory activities of selected Chinese medicinal plants and their relation with antioxidant content. BMC Complement Altern Med 12:173

8. Wang C, Levis GBS, Lee EB, Levis WR, Lee DW, Kim BS, Park SY, Park E (2004) Platycodin D and D3 isolated from the root of Platycodon grandiflorum modulate the production of nitric oxide and secretion of TNF- $a$ in activated RAW 264.7 cells. Int J Immunopharmacol 4:1039-1049

9. Zhao H, Sim J, Shim S, Ha Y, Kang S, Kim Y (2005) Antiobese and hypolipidemic effects of platycodin saponins in diet-induced obese rats: evidences for lipase inhibition and calorie intake restriction. Int J Obes 29:983

10. Lee KJ, Kim JY, Choi JH, Kim HG, Chung YC, Roh SH, Jeong HG (2006) Inhibition of tumor invasion and metastasis by aqueous extract of the radix of Platycodon grandiflorum. Food Chem Toxicol 44:1890-1896

11. Saeki T, Koike K, Nikaido T (1999) A comparative study on commercial, botanical gardens and wild samples of the roots of Platycodon grandiflorum by HPLC analysis. Planta Med 65:428-431

12. Peng Y, Zhang F, Tao H, Wang W, Sun L, Chen W, Wang C (2015) Simultaneous determination of multiple platycosides with a single reference standard in Platycodi Radix by high-performance liquid chromatography coupled with evaporative light scattering detection. J Sep Sci 38:3712-3719

13. Yoo DS, Choi YH, Cha MR, Lee BH, Kim SJ, Yon GH, Hong KS, Jang YS, Lee HS, Kim YS (2011) HPLC-ELSD analysis of 18 platycosides from balloon flower roots (Platycodi Radix) sourced from various regions in Korea and geographical clustering of the cultivation areas. Food Chem 129:645-651

14. Kim TH, Lee BE, Kim EJ, Choi YS, Lee KS, Kim HR (2014) Kim HG (2014) Determination of platycodin D and platycodin D3 in rat plasma using liquid chromatography-tandem mass spectrometry. Sci World J. 2014:231293.

15. Li W, Sun YS, Wang Z, Zheng YN (2012) Isolation and purification of saponins from Platycodon grandiflorum by semi-preparative high performance liquid chromatography and LC/ESI-MS. J Liq Chromatogr Relat Technol 35:547-557

16. Pei L, Bao Y, Ma L, Wang Q, Ye Y, Han X, Liu S, Chen X (2012) A sensitive method for determination of platycodin $D$ in rat plasma using liquid chromatography/tandem mass spectrometry and its application to a pharmacokinetic study. Planta Med 78:244-251

17. Qin Z, Zhang F, Shou-Hong G, Fei C, Jiang B, Lian-Na S, Wan-Sheng C (2014) An HPLC-MS/MS method for the quantitative determination of platycodin D in rat plasma and its application to the pharmacokinetics of Platycodi Radix extract. Chin J Nat Med 12:154-160

18. Ha YW, Na YC, Seo JJ, Kim SN, Linhardt RJ, Kim YS (2006) Qualitative and quantitative determination of ten major saponins in Platycodi Radix by high performance liquid chromatography with evaporative light scattering detection and mass spectrometry. J Chromatogr A 1135:27-35

19. Jeong EK, Cha HJ, Ha YW, Kim YS, Ha IJ, Na YC (2010) Development and optimization of a method for the separation of platycosides in Platycodi Radix by comprehensive two-dimensional liquid chromatography with mass spectrometric detection. J Chromatogr A 1217:4375-4382

20. Na YC, Ha YW, Kim YS, Kim KJ (2008) Structural analysis of platycosides in Platycodi Radix by liquid chromatography/electrospray ionization-tandem mass spectrometry. J Chromatogr A 1189:467-475

21. Zhang L, Wang Y, Yang D, Zhang C, Zhang N, Li M, Liu Y (2015) Platycodon grandiflorus - an ethnopharmacological, phytochemical and pharmacological review. J Ethnopharmacol 164:147-161

22. Jeong EK, Ha IJ, Kim YS, Na YC (2014) Glycosylated platycosides: identification by enzymatic hydrolysis and structural determination by LC-MS/MS. J Sep Sci 37:61-68

23. Dong L, Luo Y, Cheng B, Zhang Y, Zhang N, Hou Y, Jiang M, Luo G, Bai G (2013) Bioactivity-integrated ultra-performance liquid chromatography/ quadrupole time-of-flight mass spectrometry for the identification of nuclear factor-kB inhibitors and $\beta 2$ adrenergic receptor agonists in Chinese medicinal preparation Chuanbeipipa dropping pills. Biomed Chromatogr 27:960-967

24. Zhang F, Zhan Q, Gao S, Dong X, Jiang B, Sun L, Tao X, Chen WS (2014) Chemical profile-and pharmacokinetics-based investigation of the 
synergistic property of Platycodonis Radix in Traditional Chinese Medicine formula Shengxian Decoction. J Ethnopharmacol 152:497-507

25. Lee JW, Ji SH, Kim GS, Song KS, Um Y, Kim OT, Lee Y, Hong CP, Shin DH, Kim CK, Lee SE, Ahn YS, Lee DY (2015) Global profiling of various metabolites in Platycodon grandiflorum by UPLC-QTOF/MS. Int J Mol Sci 16:26786-26796

26. Ishii H, Tori K, Tozyo T, Yoshimura Y (1984) Saponins from roots of Platycodon grandiflorum. Part 2. Isolation and structure of new triterpene glycosides. J Chem Soc Perkin Trans 1:661-668

27. He Z, Qiao C, Han Q, Wang Y, Ye W, Xu H (2005) New triterpenoid saponins from the roots of Platycodon grandiflorum. Tetrahedron 61:2211-2215

28. Li W, Xiang L, Zhang J, Zheng YN, Han LK, Saito M (2007) A new triterpenoid saponin from the roots of Platycodon grandiflorum. Chin Chem Lett 18:306-308
29. Choi YH, Yoo DS, Cha MR, Kim YS, Lee HS, Lee KR, Ryu SY (2008) Platyconic acid $\mathrm{A}$, a genuine triterpenoid saponin from the roots of Platycodon grandifforum. Molecules 13:2871-2879

30. Zhang F, Li M, Qiao L, Yao Z, Li C, Shen X, Wang Y, Yu K, Yao X, Dai Y (2016) Rapid characterization of Ziziphi Spinosae Semen by UPLC/Qtof MS with novel informatics platform and its application in evaluation of two seeds from Ziziphus species. J Pharm Biomed Anal 2016:59-80

\section{Publisher's Note}

Springer Nature remains neutral with regard to jurisdictional claims in published maps and institutional affiliations.

\section{Submit your manuscript to a SpringerOpen ${ }^{\circ}$ journal and benefit from:}

- Convenient online submission

- Rigorous peer review

- Open access: articles freely available online

- High visibility within the field

- Retaining the copyright to your article

Submit your next manuscript at $\boldsymbol{\nabla}$ springeropen.com 